BMJ Open

Sport \&

Exercise

Medicine

\section{Can the Otago falls prevention program be delivered by video? A feasibility study}

To cite: Davis JC, Hsu CL, Cheung W, et al. Can the Otago falls prevention program be delivered by video? A feasibility study. BMJ Open Sport Exerc Med 2016;2: 000059 .

doi:10.1136/bmjsem-2015000059

- Prepublication history for this paper is available online. To view these files please visit the journal online (http://dx.doi.org/10.1136/ bmjsem-2015-000059).

Accepted 9 December 2015

CrossMark

For numbered affiliations see end of article.

Correspondence to Dr Teresa Liu-Ambrose; teresa.ambrose@ubc.ca

\section{ABSTRACT}

Objectives: We assessed the feasibility of delivering the Otago Exercise Programme (OEP) via an interactive DVD (ie, OEP-DVD) in combination with monthly physical therapist phone calls to older adults.

Design: This pre-post (baseline and 6-month follow-up) study included an intervention group ( $n=61)$ based in a rural location and a control group ( $\mathrm{n}=21)$ based in a city.

Setting: Sechelt and Vancouver, British Columbia. Participants: 82 community-dwelling adults $\geq 75$ years. Intervention: Individuals in the intervention group received the OEP-DVD and were instructed to do the exercises 3 times a week after their initial home physical therapist visit for 6 months.

Primary and secondary outcomes: Feasibility was ascertained by withdrawal rate and compliance to the OEP-DVD. The number of participants and the frequency (ie, number of times weekly) they performed the OEP exercises and walking were used to estimate compliance. The potential benefit of the OEP-DVD on falls risk profile (Physiological Profile Assessment (PPA)) and mobility were examined by comparing the change in the intervention group compared with the control group. Self-reported compliance to the exercise programme was assessed by monthly returned diary.

Results: Of the 82 participants, 2 withdrew from the OEP-DVD group and none withdrew from the control group. We obtained compliance data on $72 \%$ of participants in the intervention group. The mean OEP-DVD compliance was $87 \%$ and the mean walking compliance was $166 \%$. After adjusting for baseline PPA, baseline age, sex, baseline comorbidities, baseline cognitive status and baseline falls-related self-efficacy, there was a significant between-group improvement in the overall PPA score (OEP group pre-PPA to post-PPA score: $0.79 \pm 1.2$ to $0.7 \pm 0.9 ; p<0.05$ ) at study completion.

Conclusions: Although the OEP-DVD resulted in significant reductions in falls risk among communitydwelling older adults, there was a notable loss to followup limiting the feasibility of this approach.

\section{INTRODUCTION}

Falls are a leading geriatric syndrome ${ }^{1}$ and are the third leading cause of chronic

\section{Strengths and limitations of this study}

- The Otago Exercise Programme (OEP)-DVD was an effective strategy in significantly improving falls risk profile in older adults.

- Healthcare professionals (ie, physical therapists) that traditionally deliver the OEP are in limited supply, thus creating a need for alternative forms of delivery for the OEP.

- This study consisted of a non-randomised sample and had notable loss to follow-up and therefore may have limited internal validity.

disability worldwide. ${ }^{2}$ About $30 \%$ of community dwellers over the age of 65 experience one or more falls every year. ${ }^{3}$ Falls are the most costly injury among older people, and falls accumulate an estimated annual cost of US\$75-\$100 billion. ${ }^{4}$ Falls account for $84 \%$ of injury-related admissions to hospital, $40 \%$ of admissions to nursing homes, and a $10 \%$ increase in home care services. ${ }^{5}$ Falls are also the leading cause of fatal injury among adults over 65 years old. ${ }^{6}$

The ageing population (ie, those aged $>65$ years) is projected to grow with those aged 80 and over increasing at the fastest pace. ${ }^{7}$ As falls exponentially increase with age-related biological change, this substantial increase in the number of persons aged 80 and over will amplify the burden of falls on our healthcare system and society.

Falls are not random events ${ }^{8}$ and can be prevented through risk modification. ${ }^{9}{ }^{10}$ Key risk factors for falls include impaired physiological function, such as impaired balance. ${ }^{9}{ }^{10}$ Exercise can effectively reduce falls. ${ }^{11}$ Specifically, New Zealand researchers designed a progressive home-based strength and balance training programme tailored for seniors. ${ }^{12-16}$ This intervention-the Otago Exercise Programme (OEP)-has demonstrated benefit in four controlled or 
randomised controlled trials of community-dwelling seniors selected based on age alone (ie, $\geq 75$ years old). ${ }^{12-15}$ It is most effective and is cost-saving for those aged $>80$ years. ${ }^{16}$ Hence, the OEP qualifies as primary falls prevention (ie, preventing falls among those without a history of falls). The Cochrane Collaboration ${ }^{11}$ explicitly identifies the OEP as an exercise programme with strong evidence for falls reduction.

The OEP is designed to be delivered by a physical therapist. ${ }^{12-16}$ However, there are shortages of physical therapists in many settings including in rural communities. ${ }^{17}$ This combined with the fact that older adults who live in rural areas face an increased risk of falls ${ }^{2}$ highlights the need to consider and identify other methods of delivering the OEP to these individuals. There may also be potential issues of compliance to OEP if there is not the same level of home visit and telephone support as in the original trials, as evidenced by a reduced efficacy of the OEP exercises when compliance is poor with home exercise booklets. ${ }^{18}$

There is a need to consider and identify alternative methods of delivering effective falls prevention strategies, such as the OEP, to older adults because: (1) the population of older adults is projected to grow significantly; ${ }^{19}$ (2) there is already a considerable burden of falls $;^{20}$ and (3) there are limited healthcare resourcesespecially in rural communities. ${ }^{21}$

Thus, we conducted a study to assess the feasibility of delivering the OEP via an interactive DVD (ie, OEP-DVD) in combination with monthly physical therapist phone calls to older adults in the rural community of Sechelt, British Columbia (BC), Canada. Specifically, we: (1) assessed the feasibility of delivering the revised OEP-DVD to older adults of Sechelt by monitoring selfreported walking and exercise compliance and observed withdrawal rates; and (2) described the physical benefits of the revised OEP-DVD by comparing the fall risk profile of those in the intervention compared with those in the control group. Of note, we chose to utilise DVD technology because DVDs are a viable option for delivering health and lifestyle interventions. ${ }^{22}$ Data demonstrate that exercise DVDs experienced an annual growth of $11.2 \%$ from 2008 to 2012. Further, over $20 \%$ of such DVDs were purchased by older adults. ${ }^{22}$

\section{METHODS}

\section{Study design}

We used a pre-post test study with a control group. Assessors were trained by the research team and were blinded to group allocation of the participants. Assessments occurred in the participant's home at baseline (pre) and at 6 months (post). This study was approved by the Clinical Research Ethics Board at the University of British Columbia (H11-01604). All participants enrolled in this study signed written and informed consent.

\section{Participants and setting}

We included a sample of 61 old adults aged 75 years and older living in Sechelt. The District of Sechelt is centrally located on the Sunshine Coast and has a population of 9200 . In 2006, older adults comprised $25.3 \%$ of Sechelt's then- 8400 residents, compared with $14.6 \%$ for $\mathrm{BC}$ overall. Specifically, there were approximately 1550 Sechelt residents between the ages of 65 and 79 and 600 residents aged 80 and over (http://www.secheltseniors. $\mathrm{ca} /$ documents/ReporttotheCommunity.pdf). As such Sechelt met the 'rural' designation. In addition, we recruited 21 older adults aged 75 years and older to serve as a control group; all participants in this group were recruited from Metro Vancouver, BC, to minimise contamination. The sample size was one of convenience and represented the maximum number of participants we could recruit with the resources available; no formal sample size calculation was made.

We recruited via newspapers and worked with local physical therapists to promote recruitment. We included those living in Sechelt (intervention) and Vancouver (control) who: (1) were aged $\geq 75$ years; ${ }^{16}$ (2) were community-dwelling (ie, not residing in a nursing home, extended care unit or assisted-care facility); (3) had a Mini-Mental State Examination (MMSE) score $>24,{ }^{20}(4)$ were able to walk $100 \mathrm{~m}$ independently (with or without an assistive device); (5) owned an operating DVD player and television; and (6) were able to provide informed consent.

We excluded those who had: (1) a previous diagnosis of neurodegenerative disease; (2) a previous diagnosis of dementia; (3) had a stroke; or (4) a history indicative of carotid sinus sensitivity (ie, syncopal falls).

\section{Measures}

\section{Descriptive variables}

We collected information regarding age and years of education. We measured height $(\mathrm{cm})$, weight $(\mathrm{kg})$, blood pressure $(\mathrm{mm} \mathrm{Hg})$, and calculated waist-to-hip ratio. Comorbidities, such as type 2 diabetes, hypertension and dyslipidaemia, were assessed with the Functional Comorbidity Index (FCI). ${ }^{23}$ We used the Geriatric Depression Scale (GDS) ${ }^{24}$ to screen for depression. Current level of physical activity was determined by the Physical Activities Scale for the Elderly (PASE) selfreport questionnaire. ${ }^{25}$ We assessed global cognition and executive function using the MMSE ${ }^{26}$ and the Montreal Cognitive Assessment (MoCA). ${ }^{27}$ It is scored on a 30-point scale with a median score of 28 for healthy community-dwelling octogenarians with more than 12 years of education. ${ }^{26}$ The MoCA, a 30-point test, covers eight cognitive domains: (1) attention and concentration; (2) executive functions; (3) memory; (4) language; (5) visuoconstructional skills; (6) conceptual thinking; (7) calculations and (8) orientation. ${ }^{27}$ Scores below 26 are considered to be indicative of possible mild cognitive impairment. ${ }^{27} \mathrm{~A}$ bonus point is given to individuals with less than 12 years of education. General 
health, falls history in the past 6 months $^{28}$ and socioeconomic status were assessed using questionnaires and interview.

\section{Physical performance measures}

The Short Performance Physical Battery (SPPB): For the SPPB, participants were assessed on performances of standing balance, walking and sit-to-stand performance. Each component is rated out of four points, for a maximum of 12 points; a score $<9 / 12$ predicts subsequent disability. ${ }^{29}$

Physiological Falls Risk: All participants underwent a falls risk assessment at baseline (ie, at recruitment) and at trial completion (ie, at 6 months). We used the Physiological Profile Assessment (PPA) ${ }^{30}$ to assess falls risk. The PPA is a valid and reliable tool for falls risk assessment. Based on the performance of five physiological domains (postural sway, hand reaction time, quadriceps strength, proprioception and edge contrast sensitivity), the PPA computes a falls risk score for each individual, and this measure has a $75 \%$ predictive accuracy for falls in older people. ${ }^{30} \mathrm{~A}$ PPA z-score of $0-1$ indicates mild risk, 1-2 indicates moderate risk, 2-3 indicates high risk, and 3 and above indicates marked risk. $^{31}$

\section{Falls-related self-efficacy}

Self-efficacy is associated with cognitive function ${ }^{32}$ and mobility. ${ }^{33-35}$ The 16-item Activities-Specific Balance Confidence (ABC) Scale $^{36}$ assesses falls-related selfefficacy with each item rated from $0 \%$ (no confidence) to $100 \%$ (complete confidence).

\section{Intervention group}

The OEP is an individualised programme. ${ }^{13}$ It consists of strengthening exercises for the knee extensors and flexors, ankle plantarflexors and dorsiflexors, and hip abductors. The balance exercises consist of knee bends, backwards walking, walking and turning around, sideways walking, tandem stance, tandem walk, one leg stand, heel walking, toe walking, heel toe walking backwards, and sit to stand. The OEP should be performed three times per week for $30 \mathrm{~min}$.

The original OEP was designed to be delivered by a physical therapist. ${ }^{13}$ The physical therapist makes five home visits over the course of 6 months. In the first visit, the physical therapist prescribes a set of suitable OEP exercises. Progressive adjustments to the exercises are made in the three subsequent visits (ie, 2, 4 and 8 weeks after initial visit). The last visit occurs at 6 months after programme initiation. During this visit, the physical therapist ensures that the exercises are being done correctly to ensure maximum benefit.

In this study, we deliver the OEP in an adapted form (ie, we developed an OEP-DVD). We developed an OEP-DVD that could be used as a 'follow me' (step-by-step animated instructions) video by older people at home, with the ability to choose specific exercises or to watch and follow all the way through. At the beginning of the 6-month pre-post study, all individuals enrolled in the study received one visit by a physical therapist. After a thorough assessment, the physical therapist prescribed a set of suitable exercises from the OEP-DVD and educated the participant on how to progress each exercise and how to ensure safety while exercising. The standard OEP manual was also provided as back-up reference material. Participants were instructed to do the exercises three times a week after their initial home physical therapist visit. To promote compliance as well as providing ongoing support, the physical therapist telephoned the participants once a month to discuss progress, concerns and answer any questions. Each of these telephone sessions were scheduled for $15 \mathrm{~min}$.

\section{Control group}

Individuals in the control group were assessed at baseline and 6 months and were asked to complete monthly falls calendars. After 6 months, all individuals in the control group were also given the OEP-DVD and one home visit by physical therapist.

\section{Compliance and adverse events}

Compliance to the OEP-DVD was documented on monthly calendars which were returned in prepaid preaddressed envelopes at the end of each month. Participants were required to write the letters 'EX' on the days they perform the OEP exercises. All participants were instructed to report any adverse effects due to the OEP exercises to our research coordinator, such as falls or musculoskeletal pain persisting longer than $48 \mathrm{~h}$.

A subsample of 21 of our participants also took part in a qualitative study. ${ }^{37}$ Specifically, two small group interviews were initially conducted to explore the breadth of participants' experiences with the OEP-DVD. Subsequently, we conducted semistructured individual interviews to gain an in-depth understanding of participant experiences with the OEP-DVD.

\section{Statistical analyses}

Data distributions were initially examined using visual inspection of histograms and computation of skew and kurtosis values. Continuous data were summarised as mean (SD). Categorical data were summarised as frequency $(\%)$.

\section{Assessment of feasibility}

To assess feasibility, we calculated the withdrawal rate and the proportion of participants who performed the OEP-DVD exercises two or more times per week over the 6-month period. Withdrawals were defined as individuals who actively requested to withdraw from the study. We also tabulated the number of individuals who were lost to follow-up. Loss to follow-up was defined as individuals who we were unable to retain for a postintervention assessment within the study time frame. The OEP-DVD was deemed 'feasible' if the following three 
conditions were achieved: (1) a withdrawal rate $<10 \%$; (2) $50 \%$ of the participants performed the OEP-DVD exercises two or more times per week; and $<30 \%$ missing data overall.

\section{Potential benefit on falls risk and mobility}

The secondary focus of this study was to assess any physical benefits-specifically falls risk and mobility. Falls risk profile and SPPB at 6 months were the dependent variables for the secondary analyses. Bivariate correlations of baseline variables collected were computed to determine the strength of association with the key dependent variables (PPA score at 6 months, SPPB score at 6 months, separately). For the main analyses, a multiple linear regression model was constructed using the STATA V.13.0 regress procedure. The two dependent variables were PPA and SPPB score at 6 months. Baseline PPA and SPPB were controlled for, respectively. Covariates were included in each model based on their biological and statistical significance. Baseline PPA was controlled for in the final multivariate model where PPA at 6 months was the dependent variable.

\section{RESULTS}

\section{Participants}

Participants enrolled in this study had a mean age of 80 $(\mathrm{SD}=5)$ years with a mean baseline MoCA score of 24 $(\mathrm{SD}=4)$. The mean PPA score at baseline was 0.8 $(\mathrm{SD}=1.2)$ indicating mild falls risk (table 1$)$. There were no adverse events reported as a result of partaking in the OEP intervention exercises or walking exercises.

\section{Assessment of feasibility}

1. The first metric-feasibility—was based on withdrawal rate. If the withdrawal rate was $\leq 10 \%$, a future study of the OEP-DVD may be considered feasible. We had two $(3.3 \%)$ participants withdraw due to unrelated medical issues. In the control group, there were no $(0 \%)$ withdrawals. We had two participants in the control group who were lost to follow-up (table 2). We had $18(29.5 \%)$ individuals in the intervention group who we did not obtain a postintervention PPA score and $16(26.2 \%)$ individuals in the intervention group who we did not obtain a postintervention SPPB score (table 2).

Table 1 Baseline characteristics of trial participants $(\mathrm{N}=82)$

\begin{tabular}{|c|c|c|c|}
\hline Variable & $\begin{array}{l}\text { Control }(n=21) \\
\text { Mean }(S D) \\
\text { Frequency }\end{array}$ & $\begin{array}{l}\text { OEP }(n=61) \\
\text { Mean (SD) } \\
\text { Frequency }\end{array}$ & $\begin{array}{l}\text { Total }(\mathrm{N}=82) \\
\text { Mean }(\mathrm{SD}) \\
\text { Frequency }\end{array}$ \\
\hline Age (years) & $79.9(5.0)$ & $79.5(4.8)$ & $79.6(4.5)$ \\
\hline Height $(\mathrm{cm})$ & $172.3(44.4)$ & $166.9(9.3)$ & $168.3(23.6)$ \\
\hline \multicolumn{4}{|l|}{ Sex } \\
\hline Female & 16 & 40 & 56 \\
\hline Male & 5 & 22 & 26 \\
\hline Weight $(\mathrm{kg})$ & $73.3(20.8)$ & $76.2(16.9)$ & $75.4(17.9)$ \\
\hline \multicolumn{4}{|l|}{ Education } \\
\hline Less than grade 9 & 1 & 4 & 5 \\
\hline Grades $9-13$, without certificate or diploma & 2 & 16 & 18 \\
\hline High school certificate or diploma & 0 & 1 & 1 \\
\hline Trades or professional certificate or diploma & 3 & 4 & 7 \\
\hline Some university certificate or diploma & 1 & 8 & 9 \\
\hline University certificate or diploma & 3 & 5 & 8 \\
\hline University degree* & 11 & 23 & 34 \\
\hline MMSE score (maximum 30 points) & $28.6(1.0)$ & $28.6(1.5)$ & $28.6(1.4)$ \\
\hline MoCA score (maximum 30 points) & $24.7(3.0)$ & $24.3(3.7)$ & $24.4(3.5)$ \\
\hline Activities Specific Balance Confidence Scale & $84.6(16.7)$ & $85.1(13.8)$ & $85.0(14.5)$ \\
\hline Geriatric Depression Scale (maximum 15 points) & $0.5(1.1)$ & $0.5(1.1)$ & $0.9(1.3)$ \\
\hline Functional Comorbidity Index (maximum 18 points) & $0.1(0.4)$ & $0(0)$ & $0.02(0.22)$ \\
\hline Physical Activity Scale for the Elderly & $113(62)$ & $125(64)$ & $121(63)$ \\
\hline Standing balance & $3.5(0.8)$ & $3.8(0.5)$ & $3.87(0.6)$ \\
\hline PPA & $0.98(1.1)$ & $0.79(1.2)$ & $0.84(1.2)$ \\
\hline SPPB & $9.4(2.6)$ & $9.7(1.7)$ & $9.6(2.0)$ \\
\hline \multicolumn{4}{|l|}{ Compliance $(n=44)$} \\
\hline Walking compliance (\%) & NA & $177(88)$ & NA \\
\hline Exercise compliance (\%) & NA & $93(48)$ & NA \\
\hline Overall compliance (\%) & NA & $127(52)$ & NA \\
\hline
\end{tabular}


Table 2 Mean values (SDs) and mean change (SDs) for outcome measures

\begin{tabular}{|c|c|c|c|c|c|c|}
\hline Variable* $^{*}$ & $\mathbf{N}$ & $\begin{array}{l}\text { Baseline } \\
\text { Mean } \\
\text { (SD) }\end{array}$ & $\mathbf{n}$ & $\begin{array}{l}\text { Final } \\
\text { Mean } \\
\text { (SD) }\end{array}$ & $\mathbf{N}$ & $\begin{array}{l}\text { Mean change } \\
\text { at final from } \\
\text { baseline } \\
\text { (SD)† }\end{array}$ \\
\hline \multicolumn{7}{|l|}{ Control } \\
\hline PPA & 21 & $0.98(1.1)$ & 19 & $1.4(1.2)$ & 19 & $0.43(1.2)$ \\
\hline SPPB & 21 & $9.4(2.6)$ & 19 & $9.4(2.6)$ & 19 & $0.0(1.2)$ \\
\hline \multicolumn{7}{|l|}{ OEP } \\
\hline PPA & 61 & $0.79(1.2)$ & 41 & $0.7(0.9)$ & 41 & $-0.12(1.0)$ \\
\hline SPPB & 61 & $9.7(1.7)$ & 43 & $9.7(1.7)$ & 43 & $-0.3(1.9)$ \\
\hline \multicolumn{7}{|c|}{$\begin{array}{l}\text { *Stroop CW=stroop colour-words condition; stroop C=stroop } \\
\text { coloured-X's condition; } n=\text { newtons; } w=\text { watts; } \mathrm{m} / \mathrm{sec}=\text { metres per } \\
\text { second. } \\
\text { †Mean change for all cognitive measures=final value minus } \\
\text { baseline value. Positive change indicates improvement. Mean } \\
\text { change for all performance measures=final value minus baseline } \\
\text { value. Positive change indicates improvement. } \\
\text { OEP, Otago Exercise Programme; PPA, Physiological Profile } \\
\text { Assessment; SPPB, Short Performance Physical Battery. }\end{array}$} \\
\hline
\end{tabular}

2. The second metric of feasibility was to ascertain the compliance of participants in the OEP group. Specifically, we would deem the OEP-DVD feasible if $50 \%$ of the participants performed the OEP-DVD exercises twice per week. We had compliance data for 44 of the $61(72 \%)$ individuals enrolled in the intervention. Of these, one individual was a withdrawal from participating in the OEP-DVD and declined follow-up assessment, but this individual continued to return the monthly calendars. Of the 16 individuals who did not return their calendars, 4 reported they were unable due to health issues (ie, bypass surgery). Of the 44 individuals who did complete their calendars, $16(36 \%)$ individuals demonstrated at least $100 \%$ compliance performing the OEP-DVD exercises at least twice per week, $33(75 \%)$ individuals demonstrated at least $100 \%$ walking compliance and $30(68 \%)$ individuals demonstrated at least $100 \%$ overall compliance (ie, at least $100 \%$ walking compliance and $100 \%$ OEP compliance). Scores $>100 \%$ indicated that participants on average surpassed their OEP or walking goals set at baseline. The mean OEP-DVD compliance was 93\% (SD 48) and the mean reported walking compliance was $177 \%$ (SD 99; table 1). The overall OEP-DVD compliance (OEP exercised and walking combined) was $127 \%$ (SD 52).

\section{Potential benefit on falls risk and mobility}

From table 2, we observe that the individuals in the control group experienced an increase in falls risk from baseline to 6 months. In contrast, individuals in the intervention group experienced a decline in falls risk. To assess physical benefit, we evaluated the group effect on the PPA. After adjusting for baseline PPA, baseline age, sex, baseline FCI, baseline MoCA and baseline ABC score, we found that the OEP-DVD programme significantly reduced falls risk as compared with those in the control group $(\mathrm{p}=0.007$; table 3$)$. Specifically, the addition of the 'group' variable explained an additional $10 \%$ of variation in the model. The total variation explained by the model was $40 \%$. We did not find a significant between-group difference in SPPB scores at 6 months (table 2).

\section{DISCUSSION}

We found that the OEP could be delivered via a DVD combined with a single visit from a physical therapist. Although the OEP-DVD resulted in significant improvements in falls risk among community-dwelling older adults, there was a notable loss to follow-up potentially limiting the feasibility of this approach.

The compliance data must be interpreted cautiously as $16(26 \%)$ intervention participants did not provide compliance data. If we were to assume that these individuals were not compliant to the programme, the compliance rates drop as follows: $16(26 \%)$ individuals demonstrate at least $100 \%$ compliance performing the OEP-DVD exercises at least twice per week, $33(54 \%)$ individuals demonstrate at least $100 \%$ walking compliance and (49\%) individuals demonstrate at least $100 \%$ overall compliance (walking and OEP combined). Similarly, the analyses of the SPPB and PPA outcomes must be interpreted cautiously as $30 \%$ of participants did not provide 6 -month data. It is conceivable that the lack of engagement observed from the compliance and missing compliance data throughout the study may have contributed to the greater loss to follow-up compared with studies that have continual face-to-face interaction. These findings and the results of our qualitative study suggest further refinements in the OEP-DVD are recommended.

Specifically, we found that participants in the OEP-DVD group reported feedback classified by three summary themes: (1) individuals would be more motivated to use the DVD if the instructor were more

Table 3 Multiple linear regression summary ascertaining the impact of group (OEP vs control) on fall risk profile

\begin{tabular}{lcc}
\hline $\begin{array}{l}\text { Independent variables } \\
\text { Model }\end{array}$ & $\begin{array}{c}\text { Unstandardised } \boldsymbol{\beta} \text { (SE) } \\
\mathbf{R}^{\mathbf{2}}=\mathbf{4 0} \%\end{array}$ & $\mathbf{p}$ Value \\
\hline PPA (baseline) & $0.3(0.1)$ & $0.004^{*}$ \\
Group & $-0.7(0.3)$ & $0.007^{*}$ \\
Location & $0.1(0.2)$ & 0.649 \\
Sex & $0.06(0.26)$ & 0.806 \\
$\mathrm{Age}$ & $0.05(0.03)$ & 0.069 \\
$\mathrm{FCl}$ & $-0.6(0.5)$ & 0.186 \\
$\mathrm{ABC}$ & $-0.009(0.010)$ & 0.374 \\
MoCA & $-0.01(0.04)$ & 0.768 \\
\hline${ }^{*} \mathrm{p}<0.05$. & \\
ABC, Activities Specific Balance Confidence Scale; FCI, \\
Functional Comorbidity Index; MoCA, Montreal Cognitive \\
Assessment; OEP, Otago Exercise Programme; \\
PPA, Physiological Profile Assessment.
\end{tabular}


dynamic or higher energy in their delivery of the exercises; (2) individuals experiencing pain or fatigue were less likely to comply with using the DVD to exercise; and (3) individuals reported the opportunity for social engagement would be a positive factor to participating in the exercises if the DVD were offered in a community setting. ${ }^{38}$ Despite the barriers informed by the qualitative work, we still found a significant beneficial effect of the OEP-DVD on falls risk demonstrating noteworthy potential for falls prevention at a population level.

The use of digital media to deliver interventions like the OEP is becoming an increasingly important consideration from a rural and resource perspective. Specifically related to the OEP, in some parts of the world, the demand for physical therapists surpasses the supply. ${ }^{39}$ In addition to the general shortage of physical therapists, it is even more difficult to recruit and retain physical therapists to rural communities. ${ }^{17}$ Falls prevention is of particular importance in rural communities. First, most rural communities have large populations of older adults (and children). Second, according to the $\mathrm{WHO},{ }^{2}$ older adults who live in rural areas face an increased risk of falls. In rural communities, there is an underdevelopment of health promotion programmes, a lack of diagnostic services, poor access to emergency and acute care services, a lack of non-acute healthcare services, and underservicing of special-needs groupssuch as older adults. ${ }^{40}$ These factors likely exacerbate the risk of falling. Hence, examining alternative forms of delivery of effective falls prevention interventions should be an essential public health priority.

Interactive DVDs are an attractive strategy that are used by older adults for delivering health and lifestyle interventions such as the OEP. It should be noted that our qualitative interviews with 32 OEP-DVD participants found the DVD provided the necessary guidance at the programme onset, while allowing the flexibility for individuals to integrate their exercises in their daily life. ${ }^{37}$ Ultimately, this may contribute to better adherence to an active lifestyle in the long term. Our current results will facilitate future efforts to deliver the OEP-an effective primary falls prevention strategy ${ }^{11}$-to older adults using digital media. DVDs may also increase compliance to the OEP without regular home visits, as this has been an issue in previous research. ${ }^{18}$

This study has several strengths. The OEP-DVD is very practical. The exercise programme requires minimal equipment, the physical therapist or healthcare professional expertise is widely (although not universally) available, and seniors internationally have adopted the programme and complied with it. The innovation of this study is applying the OEP intervention to a hard to access (ie, rural) population, aiming to provide the best value for money. ${ }^{41}$

We note the following limitations. The loss to follow-up may limit the internal validity of this study. It has been suggested that greater than $20 \%$ missing data may pose a threat to the internal validity of a study. ${ }^{42}$ For example, we do not have specific information on 12 of the 16 participants who did not provide a reason for not returning their compliance reports for the intervention. The study excludes older adults who do not own a DVD player and a television. Hence, we may be excluding older adults with minimal or no disposable income (ie, low socioeconomic status). Yet, older adults with low socioeconomic status are at greater risk for poor health outcomes-including falls. We cannot expand on the external validity of this study. For example, participants were classified as low risk on the PPA, so the feasibility of this approach for people in the high-risk category is not yet established. Participants were not randomised to the intervention and control groups. In addition, the two groups are from different locations (urban vs rural). Also the control group did not receive telephone calls, so it is possible any effect in the intervention group was in whole or in part due to the telephone calls with researchers.

\section{CONCLUSIONS}

The burden of falls is significant. The challenge is to make a difference-to discover effective, ideally costeffective, interventions that prevent injurious falls and are readily translated to the population. This study provides an initial platform example of an implementation strategy that may positively improve physical outcomes for older adults at risk of sustaining future falls and provides suggestion for future implementation of the OEP.

\section{Author affiliations}

${ }^{1}$ Centre for Clinical Epidemiology and Evaluation, University of British Columbia \& Vancouver Coastal Health Research Institute (VCHRI), Vancouver, British Columbia, Canada

${ }^{2}$ Aging, Mobility, and Cognitive Neuroscience Lab, University of British Columbia, Vancouver, British Columbia, Canada

${ }^{3}$ Arthritis Research Centre of Canada, Richmond, British Columbia, Canada ${ }^{4}$ Centre for Hip Health and Mobility, University of British Columbia,

Vancouver, British Columbia, Canada

${ }^{5}$ Department of Physical Therapy, University of British Columbia, Vancouver, British Columbia, Canada

${ }^{6}$ Djavad Mowafaghian Centre for Brain Health, University of British Columbia, Vancouver, British Columbia, Canada

${ }^{7}$ eMotionLab, Glasgow Caledonian University, Glasgow, UK

${ }^{8}$ School of Health \& Life Sciences, Institute of Applied Health Research, Glasgow Caledonian University, Glasgow, UK

Acknowledgements The authors thank the study participants. Later Life Training for their expertise in putting together the script for the DVD, Simon Quig for filming and editing the DVD and Dr Morag Thow for demonstrating the exercises on the DVD.

Contributors TL-A was principal investigator for the study. TL-A, JCD, LCL, $\mathrm{PMAB}$ and KMK were responsible for study concept and design, data analysis and interpretation and reviewing of the manuscript. TL-A, LCL, JCD, JS and DAS were responsible for developing the OEP-DVD. JCD, CLH and TL-A were responsible for data analysis. JCD and TL-A drafted and revised the manuscript. CLH was responsible for data acquisition, data interpretation and critical review of the manuscript. WC was responsible for data acquisition and critical review of the manuscript.

Funding Canadian Institutes of Health Research Catalyst Grant: IAD-112237 to TL-A (principal investigator), LCL and JCD. TL-A is a Canada Research Chair in Physical Activity, Mobility, and Cognitive Neuroscience, a Michael 
Smith Foundation for Health Research (MSFHR) Scholar, a Canadian Institutes of Health Research (ClHR) New Investigator, and a Heart and Stroke Foundation of Canada's Henry JM Barnett's Scholarship recipient. JCD was funded by a CIHR and MSFHR Postdoctoral Fellowship. LCL is a MSFHR Scholar and a Canada Research Chair. CLH is a Alzheimer's Society Research Program Doctoral Trainee.

Ethics approval The authors obtained approval for the study from UBC Clinical Ethics Review Board.

Competing interests DAS is also a Director of Later Life Training, a not for profit training company that delivers training to health and fitness professionals on delivery of the OEP programme in the UK and Europe (ProFouND project).

Ethics approval UBC Clinical Research Ethics Board.

Provenance and peer review Not commissioned; externally peer reviewed.

Data sharing statement No additional data are available.

Open Access This is an Open Access article distributed in accordance with the Creative Commons Attribution Non Commercial (CC BY-NC 4.0) license, which permits others to distribute, remix, adapt, build upon this work noncommercially, and license their derivative works on different terms, provided the original work is properly cited and the use is non-commercial. See: http:// creativecommons.org/licenses/by-nc/4.0/

\section{REFERENCES}

1. Inouye SK, Studenski S, Tinetti ME, et al. Geriatric syndromes: clinical, research, and policy implications of a core geriatric concept. J Am Geriatr Soc 2007;55:780-91.

2. World Health Organization. WHO Global Report on falls prevention in older age. 2007.

3. Tinetti ME, Speechley M, Ginter SF. Risk factors for falls among elderly persons living in the community. $N$ Engl J Med 1988;319:1701-7.

4. Finkelstein EA, Chen $\mathrm{H}$, Miller TR, et al. A comparison of the case-control and case-crossover designs for estimating medical costs of nonfatal fall-related injuries among older Americans. Med Care 2005;43:1087-91.

5. Office of the Provincial Health Officer. Prevention of falls and injuries in the elderly. 2003

6. Angus E, Albert T, Chénard D, et al. The economic burden of unintentional injury in Canada: the Hygeia Group (SMARTRISK Foundation). 1998.

7. Statistics Canada. 2001 Census of Canada. 2001.

8. Grimely-Evans JG. Fallers, non-fallers and Poisson. Age Ageing 1990;19:268-9.

9. Lord S, Clark R, Webster I. Physiological factors associated with falls in an elderly population. J Am Geriatr Soc 1991;39:1194-200.

10. Lord S, Ward JA, Williams $P$, et al. Physiological factors associated with falls in older community-dwelling women. J Am Geriatr Soc 1994;42:1110-17.

11. Gillespie LD, Robertson MC, Gillespie WJ, et al. Interventions for preventing falls in older people living in the community. Cochrane Database Syst Rev 2009;(2):CD007146.

12. Campbell A, Robertson M, Gardner MM, et al. Falls prevention over 2 years: a randomized controlled trial in women 80 years and older. Age Ageing 1999;28:513-18.

13. Campbell J, Robertson M, Gardner M, et al. Randomised controlled trial of a general practice programme of home based exercise to prevent falls in elderly women. BMJ 1997;315:1065-9.

14. Robertson M, Devlin N, Gardner M, et al. Effectiveness and economic evaluation of a nurse delivered home exercise programme to prevent falls. 1: randomized controlled trial. BMJ 2001;322:697-701.

15. Robertson M, Gardner M, Devlin N, et al. Effectiveness and economic evaluation of a nurse delivered home exercise programme to prevent falls. 2: controlled trial in multiple centres. BMJ 2001;322:701-4.

16. Robertson MC, Campbell AJ, Gardner MM, et al. Preventing injuries in older people by preventing falls: a meta-analysis of individual-level data. J Am Geriatr Soc 2002:50:905-11.

17. Canadian Institutes for Health Information. Physiotherapists in Canada. 2008.

18. Iliffe $\mathrm{S}$, Kendrick D, Morris $\mathrm{R}$, et al. Multicentre cluster randomised tria comparing a community group exercise programme and home-based exercise with usual care for people aged 65 years and over in primary care. Health Technol Assess 2014;18:vii-xxvii, 1-105.

19. DuGoff EH, Canudas-Romo V, Buttorff C, et al. Multiple chronic conditions and life expectancy: a life table analysis. Med Care 2014;52:688-94.

20. Davis JC, Robertson MC, Ashe MC, et al. International comparison of cost of falls in older adults living in the community: a systematic review. Osteoporos Int 2010;21:1295-306.

21. Hennessy $\mathrm{CH}$, Buchner DM, Jordan JM, et al. The public health perspective in health promotion and disability prevention for older adults: the role of the Centers for Disease Control and Prevention. J Rural Health 2001;17:364-9.

22. Kaczanowska A. IBISWorld Industry Report OD5356 Fitness DVD Production in the US. http://www.ibisworld.com/industry/ fitness-dvd-production.html. http://www.webcitation.org/6Vejz8t7f. Secondary IBISWorld Industry Report OD5356 Fitness DVD Production in the US. http://www.ibisworld.com/industry/fitness-dvd-production. html. http://www.webcitation.org/6Vejz8t7f. 2012.

23. Groll DL, To T, Bombardier C, et al. The development of a comorbidity index with physical function as the outcome. J Clin Epidemiol 2005:58:595-602.

24. Yesavage JA. Geriatric Depression Scale. Psychopharmacol Bull 1988;24:709-11.

25. Washburn RA, McAuley E, Katula J, et al. The physical activity scale for the elderly (PASE): evidence for validity. J Clin Epidemiol 1999;52:643-51.

26. Folstein MF, Folstein SE, McHugh PR. "Mini-mental state." A practical method for grading the cognitive state of patients for the clinician. J Psychiatr Res 1975;12:189-98.

27. Nasreddine ZS, Phillips NA, Bédirian V, et al. The Montreal Cognitive Assessment, MoCA: a brief screening tool for mild cognitive impairment. J Am Geriatr Soc 2005;53:695-9.

28. Cummings S, Nevitt M, Kidd S. Forgetting falls. The limited accuracy of recall of falls in the elderly. J Am Geriatr Soc 1988;36:613-16.

29. Guralnik JM, Ferrucci L, Simonsick EM, et al. Lower-extremity function in persons over the age of 70 years as a predictor of subsequent disability. N Engl J Med 1995;332:556-61.

30. Lord S, Sherrington C, Menz H. A physiological profile approach for falls prevention. Falls in older people. Risk factors and strategies for prevention. Cambridge: Cambridge University Press, 2001:221-38.

31. Lord SR, Menz HB, Tiedemann A. A physiological profile approach to falls risk assessment and prevention. Phys Ther 2003:83:237-52.

32. Seeman T, McAvay G, Merrill S, et al. Self-efficacy beliefs and change in cognitive performance: MacArthur studies of successful aging. Psychol Aging 1996;11:538-51.

33. Davis JC, Nagamatsu LS, Hsu CL, et al. Self-efficacy is independently associated with brain volume in older women. $\mathrm{Age}$ Ageing 2012;41:495-501..

34. Liu-Ambrose T, Khan KM, Donaldson MG, et al. Falls-related self-efficacy is independently associated with balance and mobility in older women with low bone mass. J Gerontol A Biol Sci Med Sci 2006;61:832-8.

35. Liu-Ambrose T, Katarynych LA, Ashe MC, et al. Dual-task gait performance among community-dwelling senior women: the role of balance confidence and executive functions. J Gerontol A Biol Sci Med Sci 2009;64:975-82.

36. Myers A, Powell L, Maki B, et al. Psychological indicators of balance confidence: relationship to actual and perceived abilities. J Gerontol 1996;51A:M37-43.

37. Agha A, Liu-Ambrose TY, Backman CL, et al. Understanding the experiences of rural community-dwelling older adults in using a new DVD-delivered Otago exercise program: a qualitative study. Interact J Med Res 2015;4:e17.

38. Agha A, Liu-Ambrose T, Backman C, et al. Understanding the experiences of rural community-dwelling older adults in using a new DVD-delivered Otago Exercise Program: a qualitative study. Interact J Med Res 2015;4:e17.

39. Landry MD, Ricketts TC, Verrier MC. The precarious supply of physical therapists across Canada: exploring national trends in health human resources (1991 to 2005). Hum Resour Health 2007;5:23.

40. Ministerial Advisory Council on Rural Health. Rural health in rura hands: Strategic directions for rural, remote, northern and Aboriginal communities. 2002

41. Davis JC, Robertson MC, Ashe MC, et al. Does a home-based strength and balance programme in people aged $>$ or $=80$ years provide the best value for money to prevent falls? A systematic review of economic evaluations of falls prevention interventions. $\mathrm{Br} J$ Sports Med 2010;44:80-9.

42. Strauss SE, Richardson WS, Glasziou P, et al. Evidence-based medicine: how to practice and teach EBM. 3rd edn. 2005:105-21. 